\title{
Comparison of radiotherapy alone and radiotherapy with chemotherapy using adriamycin and 5-fluorouracil in bronchogenic carcinoma
}

\author{
G ANDERSON, T J DEELEY, C SMITH, AND J JANI \\ From Newport Chest Clinic, Newport, and Velindre Hospital, Cardiff
}

\begin{abstract}
Eighty-two patients with histologically confirmed lung cancer were randomly allocated to leceive either radiotherapy alone (2400-3200 rads, depending upon cell type) or the same dose of radiotherapy followed by four cycles of adriamycin and 5-fluorouracil. Eighty-one patients were evaluated and for the group as a whole survival was better in the group receiving adjuvant chemotherapy. Within cell types survival was better in the undifferentiated group assigned to receive adjuvant chemotherapy but survival in the patients with squamous tumours was not significantly prolonged. The chemotherapy was not unduly toxic.
\end{abstract}

In bronchogenic carcinoma adjuvant chemotherapy might prolong survival by shrinking or ablating tumour deposits both within the chest and in non-irradiated extrathoracic organs. In this study we compared the survival rate in patients with a bronchogenic carcinoma who were randomly allocated to receive either radiotherapy alone or radiotherapy followed by four cycles of adriamycin and 5-fluorouracil.

\section{Methods}

Eighty-two patients with a histologically confirmed bronchogenic carcinoma confined to the thorax were studied. They were all considered suitable for treatment by radical radiotherapy. The following cell types were recognised: squamous cell, small cell, adenocarcinoma, and undifferentiated tumours. Where it was impossible to determine the cell of origin the type was classified as "unspecified". Patients were excluded from the study if they had co-existent serious general disease.

Before treatment patients had a chest radiograph, blood urea, haemoglobin, white blood cell count, and liver function tests. Radioactive isotope bone, brain, and liver scans were carried out only if there was a clinical indication. A chest radiograph was taken at monthly intervals in all

Address for reprint requests: Dr G Anderson, Newport Chest Clinic 129 Stow Hill, Gwent. patients and a blood count immediately before each chemotherapy cycle in those patients receiving chemotherapy.

Each patient was allocated randomly to treatment with either radiotherapy alone or radiotherapy plus chemotherapy (the adjuvant group). Randomisation of patients was stratified by cell type and presence or absence of mediastinal node involvement. Mediastinal node involvement was diagnosed clinically by recurrent laryngeal nerve palsy or superior vena caval obstruction, radiologically by diaphragmatic paralysis or the presence of mediastinal nodes, and bronchoscopically by extrinsic tracheal compression or carinal widening.

Radiotherapy was given to the primary tumour and mediastinum using a $4 \mathrm{Mev}$ Linear Accelerator by means of two non-opposed fields, one anterior and the other posterior oblique. This treatment was given on an outpatient basis twice a week with eight treatments over the total time of 23 days, starting within one week of randomisation. The doses used were 3200 rads for squamous and adenocarcinomatous lesions and 2400 rads for undifferentiated and small cell carcinomas. An intermediate dose of 2800 rads was given for unspecified cell type.

Chemotherapy was given as four cycles at one month intervals on a day patient basis. Each cycle consisted of adriamycin $80 \mathrm{mg} / \mathrm{m}^{2}$ iv and 5 fluorouracil $1200 \mathrm{mg}$ iv. The first cycle was given 51 days after day 1 of radiotherapy. Patients re- 
ceiving radiotherapy alone were seen as outpatients at the same intervals as those receiving adjuvant treatment. Subsequently all patients were seen at monthly intervals as outpatients, and survival was measured.

\section{Results}

Eighty-two patients entered the study. One was found to have multiple metastases from a malignant melanoma at postmortem and was withdrawn from analysis. Details of the patients are shown in table 1. The groups are comparable in terms of age, sex, mediastinal node involvement, and cell type.

Table 1 Details of patients studied

\begin{tabular}{lll}
\hline Details & $\begin{array}{l}\text { Radiotherapy } \\
\text { alone }\end{array}$ & $\begin{array}{l}\text { Radiotherapy } \\
\text { chemotherapy }\end{array}$ \\
\hline No of Patients & 43 & 38 \\
Average age (yr) & 63 & $62 \cdot 4$ \\
Number of female patients & $7(16 \%)$ & $4(11 \%)$ \\
Number with Mediastinal & $19(44 \%)$ & $17(45 \%)$ \\
rode involvement & & \\
Histological cell type & & \\
Squamous & 27 & 22 \\
Undifferentiated & 7 & 4 \\
Adenocarcinoma & 2 & 1 \\
Small cell & 3 & 3 \\
Unspecified & 4 & \\
\hline
\end{tabular}

The survival rates for all the patients are shown in the figure. These were calculated using the product limit method ${ }^{1}$ and the time was measured from the first day of treatment. The patients still alive at the time of analysis in the radiotherapy group had survived one, seven, nine, 10, 22, 63, 83 , and 94 weeks and in the adjuvant group 11 , $2,56,59,118$, and 163 weeks. The figure shows the improved survival in the adjuvant group particularly after the completion of chemotherapy.
The survival data were analysed using a log rank test $^{2}$ (table 2), and for these tests the patients were subdivided according to the main features expected to affect their prognosis-namely, histological type and presence of mediastinal nodes. The overall effect of chemotherapy was determined by summating the observed and expected numbers of deaths, calculating $\chi^{2}$ for these sums and referring to standard tables with one degree of freedom. This yielded a $p$ value of $\bumpeq 0 \cdot 02$. For patients with undifferentiated tumours the observed difference in survival was almost double that shown in

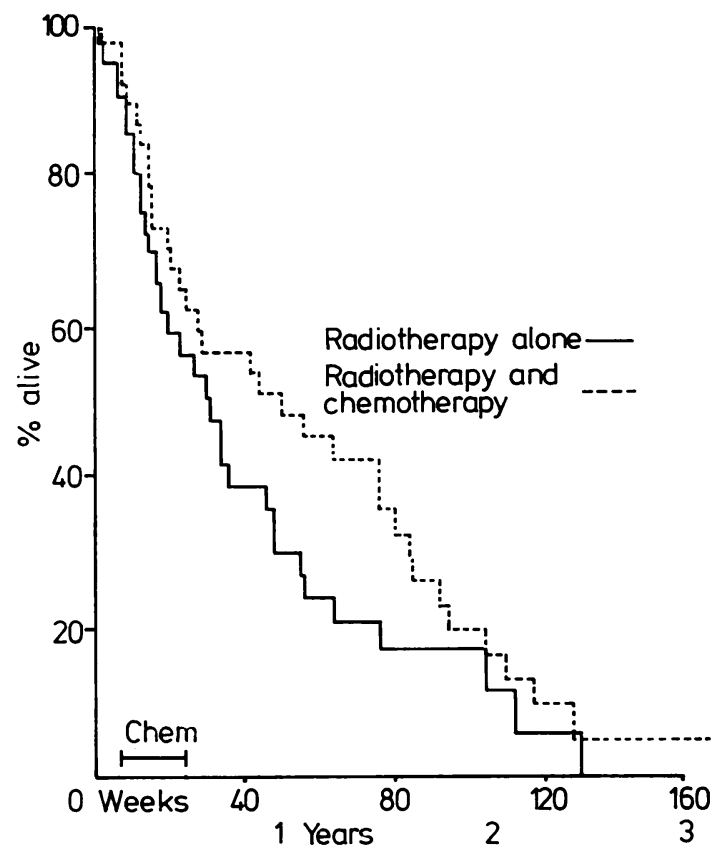

Figure Survival in carcinoma of the bronchus with and without adjuvant chemotherapy.

Table 2 Observed $(O)$ and expected $(E)$ deaths from the log rank analysis. The death rates are only relative within each row

\begin{tabular}{|c|c|c|c|c|c|c|c|}
\hline \multirow[b]{2}{*}{ Histology } & \multirow[b]{2}{*}{ Nodes } & \multicolumn{3}{|c|}{ Radiotherapy } & \multicolumn{3}{|c|}{ Radiotherapy + chemotherapy } \\
\hline & & $O$ & $E$ & $\begin{array}{l}\text { Relative } \\
\text { death rate }\end{array}$ & $O$ & $E$ & $\begin{array}{l}\text { Relative } \\
\text { death rate }\end{array}$ \\
\hline Squamous & $\begin{array}{l}\text { Positive } \\
\text { Negative }\end{array}$ & $\begin{array}{l}11 \\
10\end{array}$ & $\begin{array}{l}8 \cdot 05 \\
9 \cdot 29\end{array}$ & $\begin{array}{l}1 \cdot 08 \\
1 \cdot 37\end{array}$ & $\begin{array}{l}9 \\
9\end{array}$ & $\begin{array}{r}11.95 \\
9.71\end{array}$ & $\begin{array}{l}0.93 \\
0.75\end{array}$ \\
\hline Undifferentiated & $\begin{array}{l}\text { Positive } \\
\text { Negative }\end{array}$ & $\begin{array}{l}3 \\
4\end{array}$ & $\begin{array}{l}0.92 \\
1 \cdot 60\end{array}$ & $\begin{array}{l}3 \cdot 26 \\
2 \cdot 50\end{array}$ & $\begin{array}{l}3 \\
4\end{array}$ & $\begin{array}{l}5 \cdot 08 \\
6 \cdot 40\end{array}$ & $\begin{array}{l}0.59 \\
0.63\end{array}$ \\
\hline Others & $\begin{array}{l}\text { Positive } \\
\text { Negative }\end{array}$ & $\begin{array}{l}3 \\
4\end{array}$ & $\begin{array}{l}2 \cdot 75 \\
3 \cdot 14\end{array}$ & $\begin{array}{l}1 \cdot 09 \\
1 \cdot 28\end{array}$ & $\begin{array}{l}3 \\
4\end{array}$ & $\begin{array}{l}3 \cdot 25 \\
4 \cdot 86\end{array}$ & $\begin{array}{l}0.92 \\
0.82\end{array}$ \\
\hline Total & & 35 & $25 \cdot 75$ & $1 \cdot 24$ & 32 & $41 \cdot 25$ & 0.83 \\
\hline
\end{tabular}


the figure and this is reflected in the relative death rates of table 2 . Although the $p$ value was $<0.02$ the numbers were only 15 . For the histological subdivision of squamous carcinoma there was a $p$ value of $\bumpeq 0.25$ from 49 patients.

The incidence of toxicity is shown in table 3 . All patients surviving beyond cycle 2 experienced total alopecia but hair regrew after the fourth cycle. Four patients developed leucopenia (white cell count $500-3000 / \mathrm{cu} \mathrm{mm}$ ). This produced no illeffects in three patients but one developed a transient pneumonia. A sore throat and tongue occurred in six patients and in two it was severe. Three patients developed a transient profuse nasal discharge. Adriamycin-induced cardiomyopathy did not occur.

\section{Discussion}

Earlier studies of adjuvant chemotherapy with radiotherapy have yielded conflicting results. When radiotherapy in tumour doses of 4000-5000 rads was added to nitrogen mustard, ${ }^{3}$ vinblastine, ${ }^{4}$ or procarbazine $^{5}$ there was no improvement in survival but these drugs are relatively ineffective in lung cancer. Carr et $a^{8}$ studied 188 patients with a variety of histological types of lung cancer who were allocated to receive $4500-5000$ rads of radiotherapy alone or the same tumour dose combined with 5 -fluorouracil $10 \mathrm{mg} / \mathrm{kg}$ iv daily for five days. Survival was not improved in the adjuvant group for any cell type. Almost all these patients developed irradiation oesophagitis and the majority of those receiving chemotherapy showed toxic drug reactions. It is possible that any benefit from the chemotherapy might have been masked by deaths from the combination of the large doses of radiotherapy and chemotherapy. Another study ${ }^{7}$ showed that tumour regression in a group of lung cancer patients was equivalent in patients given 2000 rads plus 5-fluorouracil to those given $\mathbf{4 0 0 0}$ rads alone while regression in both groups was better than in a third group receiving 2000 rads alone. This study failed to show any benefit on survival from giving 5-fluorouracil. A recent Medical Research

Table 3 Incidence of side-effects in 38 patients assigned to adjuvant chemotherapy (36 survived to receive it)

\begin{tabular}{ll}
\hline Side effect & Number of patients \\
\hline Alopecia & All patients surviving beyond cycle 2 \\
Sore throat & 6 \\
Vomiting & 4 \\
Transient leucopenia & 4 \\
Rhinitis & 3 \\
\hline
\end{tabular}

Council Study has shown in localised small cell carcinoma that survival is better if a combination of cyclophosphamide, methotrexate, and CCNU was added to radiotherapy. ${ }^{8}$

In our study the combination used is known to be active in lung cancer. ${ }^{9}$ The radiotherapy dosage level was relatively low because it has been demonstrated that survival is better and morbidity less if patients receive 3000 rads than $4000 .^{10}$ Survival was significantly better for the adjuvant group as a whole and within groups for the undifferentiated tumours, where there was a worthwhile prolongation of life. The term undifferentiated carcinomas is likely to include large cell carcinomas and sone less well-differentiated squamous and adenocarcinomas. It is less precise than the classification of the World Health Organisation (WHO), ${ }^{11}$ but in patients receiving radiotherapy the histological classification is usually made from small tumour fragments obtained from sputum cytology or bronchoscopy. The WHO classification is useful for the large tissue samples obtained at resection or necropsy but may give a misleading air of precision if samples are small.

The combination of cytotoxic drugs used did not prove unacceptably toxic and it is possible that these results might be improved with newer drug combinations.

\section{References}

1 Kaplan EL, Meir P. Nonparametric estimation from incomplete observations. J Am Statist Ass 1958; 53:457-60.

2 Peto R, Pike MC, Armitage P, et al. Design and analysis of randomized clinical trials requiring prolonged observation of each patient. $\mathrm{Br} \mathrm{J}$ Cancer 1977; 35:1-39.

3 Krant MJ, Chalmers TC, Dederick MM et al. Comparative trial of chemotherapy and radiotherapy in patients with non- resectable cancer of the lung. Am J Med 1963; 35:363-73.

4 Coy P. A randomized study of irradiation and vinblastine in lung cancer. Cancer 1970; 26:803-7. o

5 Landgren RC, Hussey DH, Samuels ML, Leary $N$ WV. A randomised study comparing irradiation N alone to irradiation plus procarbazine in inoperable bronchogenic carcinoma. Radiology 1973; 108:403-6.

6 Carr DT, Childs DS, Lee RE. Radiotherapy plus 5-fluorouracil compared to radiotherapy alone for $\stackrel{-}{-}$ inoperable and unresectable bronchogenic carcinoma. Cancer 1972; 29:375-80.

7 Cohen JL, Krant MJ, Shnider BL. Radiation plus 5-fluorouracil. Clinical demonstration of an $\stackrel{\mathbb{Q}}{\unrhd}$ additive effect in bronchogenic carcinoma. Cancer Chemotherapy Rep 1971; 55:253-8. 
8 Medical Research Council Lung Cancer Working Party. Radiotherapy alone or with chemotherapy in the treatment of small cell carcinoma of the lung. Br J Cancer 1979; 40:1-10.

9 Rees GJG, Bugaighis A, Anderson G. Treatment of advanced bronchogenic carcinoma with adriamycin and 5-fluorouracil. Br J Dis Chest 1975; 69: 199-206.
10 Deeley TJ. A clinical trial to compare two different dose levels in the treatment of advanced carcinoma of the bronchus. Clin Radiol 1966; 17:299-301.

11 Kreyburg L. International Histological Classification of Tumours, no 1: Histological Typing of Lung Tumours. Geneva: World Health Organisation, 1967. 